\title{
Author Correction: Constraining the rise of oxygen with oxygen isotopes
}

\author{
B. A. Killingsworth (D), P. Sansjofre, P. Philippot (D), P. Cartigny, C. Thomazo (1) \& S. V. Lalonde (D)
}

Correction to: Nature Communications https://doi.org/10.1038/s41467-019-12883-2, published online 29 October 2019.

The original version of this Article contained an error in the Source Data for Fig. 1a. This caused some of the sulfate $\Delta 33 \mathrm{~S}$ data (in dark blue open diamond symbols) from around $\sim 2.5$ to $2.6 \mathrm{Ga}$ (horizontal axis) to be displayed incorrectly in Fig. 1a. The caption of Fig. 1 remains the same and the mistake does not affect the conclusions of the paper. The Source Data file and Fig. 1a have now been corrected in the PDF and HTML versions of the Article.

Published online: 30 September 2020

cc) (i) Open Access This article is licensed under a Creative Commons Attribution 4.0 International License, which permits use, sharing, adaptation, distribution and reproduction in any medium or format, as long as you give appropriate credit to the original author(s) and the source, provide a link to the Creative Commons license, and indicate if changes were made. The images or other third party material in this article are included in the article's Creative Commons license, unless indicated otherwise in a credit

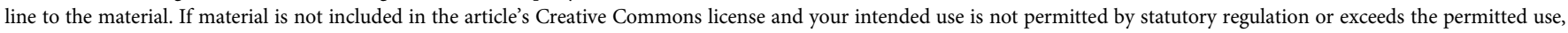
you will need to obtain permission directly from the copyright holder. To view a copy of this license, visit http://creativecommons.org/licenses/by/4.0/.

(C) The Author(s) 2020 